\title{
Exploration and Analysis on Methods and Strategies for Training of Humanistic Quality of Excellent Engineers from Internationalization Perspective
}

\author{
Xiang Shi \\ School Energy and Power Engineering, Jiangsu University, Zhenjiang, 212013, China
}

Keywords: Nationalization perspective; Engineer; Humanistic quality; Training program

\begin{abstract}
Economic relation in the world has become closer with the constant promotion of economic globalization and the relation of engineering construction in the world has also become closer to a certain extent with the constant strengthening of contact among various places in the world. As culture and national conditions of various countries in the world are different to a great extent and cultural customs of some countries are even conflicting, it is required to pay more attention to train the humanistic quality of engineers from internationalization perspective in the training process of engineers in order to make them adapted to internationalization development demand better in work. This paper discusses the humanistic quality education of engineers from internationalization perspective and expects to provide corresponding reference for the education of engineers.
\end{abstract}

\section{Introduction}

With the constant development of the times and the constant progress of science and technology, living conditions of people have developed constantly and world-wide architectural engineering industry has achieved great development. The constant development of economic globalization makes the liquidity of construction in various countries and regions wider and wider and construction output has been accepted in various places in the world. However, as culture and customs in different countries and regions are different to a great extent, it is required to think from internationalization perspective and train the humanistic quality of engineers in the education and training of engineers in order to train engineers meeting the requirement of internationalization development.

\section{Urgency to conduct internationalization humanistic quality education for engineers}

\section{Requirement for training of Chinese engineers under the condition of economic globalization}

The trend of economic globalization has constantly accelerated in the current world. With the development of economic globalization, the economic relation in the world has become increasingly closer, the flow of cash, trade, labor and resources has constantly accelerated and the construction of various countries in the world has turned to optimal allocation of resources around the world from dependence on internal national resources ${ }^{[1]}$. In the current world, the economic development of some developed countries has entered a high stage and the construction market in China has passed the phase of prosperity. However, some developed countries have relatively higher construction technologies. Therefore, to seize more international construction market, construction enterprises in various countries have conducted fierce competition. It is necessary to improve the competitiveness of engineering industry constantly so as to gain more construction market and obtain more foreign exchange resources.

The $21^{\text {st }}$ century is a century with unprecedented prosperous technology, which is full of various kinds of information. The competition among countries is talent competition after all which has become a key factor for the improvement of international economic competitiveness of a nation. Therefore, it is first necessary to train a batch of high-quality engineers so as to improve the competitiveness of China in construction industry. Appropriate talent training methods should be established first in the training process of high-quality engineers. Therefore, the training of 
humanistic quality of talents from internationalization perspective is a requirement of economic globalization for national development.

\section{Requirement for the implementation of opening-up strategy}

Chinese economy has achieved rapid development over 30 years since the reform and opening up. With the development of Chinese economy, Chinese engineering construction industry has entered unprecedented prosperity phase. With the constant development of Chinese engineering construction industry, the technical level of Chinese engineering construction has improved constantly. Most technologies have been compatible internationally. China has even achieved international leading effect and won the confirmation of the world. This lays a foundation for the entry of Chinese engineering industry into the international market. With the constant implementation of "going-out" strategy of Chinese economic development, many Chinese enterprises have started to go to the world market and a batch of transnational enterprises with good benefit have emerged. However, with the constant implementation of Chinese "going-out" strategy, Chinese enterprises have exposed a series of problems in overseas development, such as the lack of engineers especially engineers with high cultural quality ${ }^{[2]}$. The development of overseas enterprises concerns not only the profit and benefit of enterprises, but also the national image to a great extent. Therefore, to adapt to the development of Chinese "going-out" strategy, it is necessary to strengthen the training of engineers and train excellent engineers with high cultural quality from internationalization perspective.

\section{Requirement for the development of a powerful country in education}

The education of a country directly concerns the future of a nation. To achieve great rejuvenation of Chinese nation, China needs a batch of high-quality talents. The competition in the $21^{\text {st }}$ century is talent competition after all. Talents should be trained by education. The adaptation of educational pattern and system to social development demand directly influences the quality of talents.

Substantial economy is always a huge engine of the world economy in the process of world economic development. If substantial economy goes into recession, the whole economy will be floundering. For example, as everyone knows, the economic crisis of America in 1930s was resolved through the construction of substantial economy such as the construction of large water conservancy project to a great extent. Engineers play a vital role in the construction of substantial economy. Therefore, it is necessary to strengthen the training of engineers and train a batch of excellent engineers with high humanistic quality from internationalization perspective for making contributions to the powerful nation strategy in order to grab chances in the international market.

\section{Corresponding locating for the training of excellent engineers}

In the process of talent training, it is necessary to first conduct corresponding locating for talent training objective. Only when knowing what kind of talents to be trained can China establish corresponding talent training mode in the process of talent training ${ }^{[3]}$. For excellent engineers, it is necessary to make engineers have professional skills adapted to the international standard from internationalization perspective. In addition, excellent engineers should have corresponding humanistic quality. During engineering design, engineers should not only consider professional needs, but also respect cultural atmosphere in different regions and integrate cultural connotations in different regions into architectural design so that architectural works can integrate with living customs of local people very well.

In the process of technical training of engineers, it is necessary to make undergraduate engineers understand the most fundamental production link of products and have basic understandings of project operation, maintenance and construction. In the training process of postgraduates, it is necessary to make them understand each link ranging from product design to development. Products designed should have certain competitive advantages. In addition, doctoral students should conduct complicated research and development of industrial products and have corresponding competitiveness in foreign countries. 
In the training process of humanistic quality of engineers, on the one hand, engineers should understand the law, culture and customs of a nation and the life of local people, integrate into their life and communicate with local people in the training process. On the other hand, engineers should be able to gain recognition of internationalization. Undergraduates should have certain international cultural horizon and be able to communicate with local people. Postgraduates should be able to design some industrial products according to local cultural customs. Doctoral students should be able to communicate and cooperate with local people from internationalization perspective.

\section{Specific practice for the training of cultural quality of excellent engineers from internationalization perspective}

\section{Establish international course system}

In the establishment of international programs, it is necessary to form an international course system with Chinese characteristics. It is required to establish courses according to students' capability of acceptance and teaching objectives based on the practical situation of China rather than copying western educational pattern blindly ${ }^{[4]}$.

The following forms are generally adopted in the establishment of international courses. First, informative lecture. The specific development of some countries and regions, especially their culture and customs, can be introduced to students through specific informative lectures so that they can understand the specific development state of some countries. For example, students can understand the culture and customs of Arab countries and take such information into consideration in the future engineering design work through informative lectures on Arab countries. Second, special report. Students can understand problems with common attention of the world in learning, pay attention to such problems in future product design and design products from internationalization perspective through discussions in special report. For example, students can understand the public problem of global warming and effectively avoid the problem in future design through a special lecture on global warming issue. Third, international courses. It is necessary to provide knowledge such as international law, international trade and international organization in specific learning so that students can master international rules in the learning process and protect their legal interests with international rules in future international affairs.

To sum up, it is required to establish appropriate international course projects according to the specific development of the international society and the specific status of the nation in the training process of excellent engineers.

\section{Use international teaching methods}

Besides the establishment of international courses appropriate to national development in the training of humanistic quality of excellent international engineers, it is also necessary to adopt international teaching methods in the teaching process and train engineers' feeling of humanistic quality from internationalization perspective ${ }^{[5]}$.

In the specific teaching process, teachers must have teaching emphasis in class according to international teaching methods, which should be established according to the training objective of humanistic quality of excellent engineers. In addition, teachers should also train students' abilities of independent study and cooperative study in class. Teachers can assign some learning tasks to students a few minutes before the end of class. Meanwhile, teachers should group students with generally 3 to 5 students in each group and train students' independent ability and ability of teamwork with the method of group learning and independent data searching. In the specific teaching, teachers should also train students' thinking, especially their creative thinking and critical thinking. On the one hand, teachers should raise corresponding questions actively and ask students to give their own opinions in the specific teaching process. In addition, teachers can ask students to think with reverse thinking. For example, in the teaching of religious problems, teachers should make students understand that religion can promote national unity and meanwhile cause religious war, and ask 
students to give their own opinions and form their own religious views on the basis of this teaching objective.

\section{Change traditional foreign language teaching mode}

For the training of humanistic quality of excellent engineers from internationalization perspective, foreign language is a skill to be mastered by engineers. Only with a foreign language can students go deep into the local life, really understand local cultural connotations and customs through communication and form their real cultural quality.

Attention is often only paid to examination in traditional foreign language teaching. However, such exam-oriented education often improves students' test ability, but results in dumb English in many cases. All this will reduce students' practical ability. Therefore, it is necessary to change the traditional English teaching mode in order to train international humanistic quality of excellent engineers. First, it is required to train students' ability of practical use of language and improve their language communication ability. Second, foreign language teaching and students' specialized course education should be combined so that students can communicate with local people directly in their future work in foreign countries.

\section{Establish international teaching team}

Teachers often play an important role in talent training process. Besides the training of specific knowledge, teachers should also train students' thinking correspondingly. In international teaching process, teachers are like a window through which students can understand the world. Therefore, a batch of high-quality teachers is needed for training humanistic quality of excellent engineers.

Internationalized teachers should have overseas life experience, master a foreign language skillfully and the specific experience of attending international engineering projects. Moreover, some foreign teachers should be employed. Compared to Chinese teachers, foreign teachers often have deeper understandings of local customs and culture in the training process of students' humanistic quality.

\section{Conclusion}

With the constant development of economic globalization, the competition among various countries has become increasingly fierce. To win the initiative of economic development in fierce international competition, China should train a large batch of excellent engineers with national horizon and high cultural quality.

\section{Acknowledgments}

This paper is a specific subject of humanistic and social sciences research of the Ministry of Education in 2013 (13jdsz3011) and a subject of work seminar of instructors in colleges and universities in Jiangsu Province (14fyhlx02).

\section{References}

[1] Lu Yanqing, Li Jihuai. Analysis on Realization Approach for Training of Excellent Engineers Take Metallurgical Engineering Major in Liaoning University of Science and Technology for Example. Heilongjiang Researches on Higher Education, 2013, 31(5):67-69.

[2] Li Yan. Research on Training of Excellent Engineers Based on CDIO in China. Central South University, 2012.

[3] Xi Furong, Li Hao. Brief Analysis on Training of Humanistic Quality of Engineers. Heihe Journal,2013(10):161-162. 
[4] Guo Jianping. Theoretical Logic and Practice of Humanistic Quality Training - Based on the Perspective of University Talents' Growth in Science and Engineering. Wuhan University of Technology,2012.

[5] Yang Denglu, Luo Yongmei. Definition of Role of College Instructors in Educational Training Plan of Excellent Engineers. Sci-tech Entrepreneurs, 2011,(1):204. 